\title{
MEUS HERÓIS: LEMBRANÇAS DISCENTES NO ENSINO DE HISTÓRIA
}

\author{
Israel Soares de Sousa, Universidade Federal de Campina Grande (UFCG) \\ israelhistoria@gmail.com \\ Raquel Leão de Bastos, Prefeitura Municipal de João Pessoa \\ leaodebastos@gmail.com
}

\begin{abstract}
RESUMO
O presente artigo é resultante de parte de nossa pesquisa de doutorado, realizada entre os anos de 2012 e 2013, no município de João Pessoa, Paraíba, e tem como finalidade problematizar o Ensino de História enquanto uma prática pedagógica ainda muito arraigada na concepção elitista dos grandes homens e heróis como transformadores dos processos históricos. Para tanto, discutimos aqui, as principais memórias discentes em relação às suas aprendizagens na disciplina de História quando se trata das personagens históricas lembradas durante suas trajetórias escolares no Ensino Médio em uma escola pública do referido município. Corroboramos com a necessidade da História e de seu ensino nas escolas dialogar com as histórias locais e trazer para suas vivências os movimentos sociais, as diversidades, os sujeitos "de baixo" que lutam e que transformam os rumos da história. Assim, defendemos um Ensino de História mais justo e democrático, que não apague as memórias não oficiais, mas que dialogue com elas, principalmente nos espaços escolares da Educação Básica pública.
\end{abstract}

PALAVRAS-CHAVE: Ensino de História; Memória; Heróis Nacionais.

\section{MY HEROES: MEMORIES OF STUDENTS IN THE TEACHING OF}

\section{HISTORY}

\begin{abstract}
This article is the result of part of our doctoral research, carried out between the years of 2012 and 2013, in the city of João Pessoa, Paraíba, and aims to problematize the Teaching of History as a pedagogical practice still very much rooted in the elitist conception of Great men and heroes as transformers of historical processes. For that, we discuss here the main learning memories in relation to their learning in the discipline of History when it comes to the historical characters remembered during their high school trajectory in a public school of the mentioned municipality. We corroborate with the need of History and its teaching in schools to dialogue with local histories and to bring to their experiences the social movements, the diversities, the "lower" subjects that fight and that transform the course of history. Thus, we advocate a more just and democratic Teaching of History that does not erase unofficial memories, but rather dialogue with them, especially in the public elementary school spaces
\end{abstract}

KEYWORDS: History teaching; Memory; National Heroes. 


\section{MIS HEROS: RECUERDOS DE ESTUDIANTES EN LA ENSEÑANZA DE HISTORIA}

\section{RESUMEN}

El presente artículo es resultado de parte de nuestra investigación de doctorado, realizada entre los años 2012 y 2013, en el municipio de João Pessoa, Paraíba, y tiene como finalidad problematizar la Enseñanza de Historia mientras una práctica pedagógica aún muy arraigada en la concepción elitista de los Grandes hombres y héroes como transformadores de los procesos históricos. Para ello, discutimos aquí, las principales memorias discentes en relación a sus aprendizajes en la disciplina de Historia cuando se trata de los personajes históricos recordados durante sus trayectorias escolares en la Enseñanza Media en una escuela pública del referido municipio. Corroboramos con la necesidad de la historia y de su enseñanza en las escuelas dialogar con las historias locales y traer a sus vivencias los movimientos sociales, las diversidades, los sujetos "de bajo" que luchan y que transforman los rumbos de la historia. Así, defendemos una Enseñanza de Historia más justa y democrática, que no borre las memorias no oficiales, sino que se relacione con ellas, principalmente en los espacios escolares de la Educación Basica publica.

PALABRAS CLAVES: Enseñanza de Historia; Memoria; Héroes Nacionales.

\section{INTRODUÇÃO}

O Ensino de História ainda se constitui como um desafio de democratização nas suas vivências, seja nos aspectos teóricos, seja nas metodologias aplicadas em sala de aula. Nesse sentido, partimos do pressuposto de que, mesmo com os avanços em muitas áreas da Educação Básica, o ranço positivista e seu memorialismo ainda permeiam boa parte das práticas pedagógicas de professores de História. Por isso, não são raras aulas expositivas, aplicação de questionários para serem decorados para as avaliações escritas, o uso exclusivo do livro didático, práticas que conduzem os alunos à posição de passividade em relação ao conhecimento.

Até o final do século passado, a concepção predominante de História era de disciplina que estuda o passado, o que também influenciou a tradição do ensino de História, e mesmo com muitas mudanças de perspectivas e a compreensão mais democrática do saber de muitos professores, ainda se baseia na transmissão e memorização dos conteúdos, datas comemorativas, homens importantes na política ou guerras que mudaram os destinos da humanidade. É essa concepção que podemos destacar como um dos elementos que, mesmo no século XXI, ainda contribui na falta de interesse dos alunos por estudar história, pois a 
transmissão de fatos desprendidos de suas realidades, muitas vezes de forma aleatória, além de não coadjuvar para uma percepção mais contextualizada e crítica do mundo, pode alienar as interpretações da realidade dos mesmos, concorrendo para que os sujeitos deixem de participar ativamente da sociedade, fragilizando a construção das identidades sociais e inibindo seus sentimentos de pertencimento aos espaços de vivências.

Por outro lado, com as mudanças introduzidas a partir da organização educacional desde 1996, com a Lei de Diretrizes e Bases da Educação Nacional - LDB, uma série de documentos buscou reconfigurar o ensino e, consequentemente, a História e suas práticas docentes. Nesse sentido, o discurso da democratização dos saberes e a consideração dos conhecimentos prévios dos alunos têm, por vezes, desembocado no esvaziamento dos conteúdos escolares e, no caso da História, contribuído para subtração do factual sem deixar elementos significativos do lugar. Um dos elementos que apontamos para consolidação dessa situação, que contribui consideravelmente para uma educação de baixa qualidade, diz respeito à formação dos professores, que vem sendo abarcada com políticas públicas que não se fazem eficazes e condizentes com as realidades educacionais dos ambientes escolares e dos seus entornos.

\section{ENSINO DE HISTÓRIA E MEMÓRIAS DISCENTES}

No intuito de perceber o que os alunos consideram sobre o Ensino de História e como têm vivenciado essa disciplina durante sua trajetória escolar, realizamos uma série de questões que foram respondidas por eles e que iremos tratar a partir deste momento. Para facilitar o processo de comunicação, as questões propostas foram respondidas por formulários disponíveis na internet, o que agilizou o recebimento e sistematização das mesmas. Ressaltamos que esses questionamentos são parte da pesquisa de doutorado, que se complementa através de uma pesquisa-ação, com uso de história oral, observações de campo e grupos de discussão, mas que estes não fazem parte do artigo em questão.

Iniciamos perguntando aos mesmos se eles entendem ser importante estudar História e o porquê dessa consideração. Para viabilizarmos a sistematização das respostas, nas questões abertas, escolhemos, no universo de duzentos e cinco alunos pesquisados, apenas quinze, sendo cinco de cada ano. A escolha se deu pela representatividade das respostas, que de 
maneira geral abarcaram a totalidade dos alunos. Além disso, não teríamos como analisar todas as respostas por nossa limitação de tempo e espaço. Nesse sentido, suas afirmações foram estruturadas no quadro a seguir:

Quadro 01: Importância atribuída ao Ensino de História

\begin{tabular}{|c|c|c|}
\hline Aluno A & Aluno B & Aluno C \\
\hline $\begin{array}{l}\text { Sim. Para saber mais sobre } \\
\text { nosso passado no mundo. }\end{array}$ & $\begin{array}{l}\text { Sim. É importante o estudo da } \\
\text { história porque é sempre bom } \\
\text { aprender dos antepassados, o } \\
\text { que aconteceu e que coisas } \\
\text { mudou. }\end{array}$ & $\begin{array}{l}\text { Sim. A história mostra como } \\
\text { foi a vida dos nossos } \\
\text { antepassados e como muda as } \\
\text { coisas no passa do tempo. }\end{array}$ \\
\hline Aluno D & Aluno E & Aluno F \\
\hline $\begin{array}{l}\text { Sim. Porque é bom aprender } \\
\text { sobre o nosso antepassado } \\
\text { coisa que a gente nem saberia } \\
\text { que existisse, coisas que já } \\
\text { aconteceu. }\end{array}$ & $\begin{array}{l}\text { Sim. Porque eu acho que todos } \\
\text { nós temos a obrigação de saber } \\
\text { dos nossos familiares do } \\
\text { passado, e como foi descoberto } \\
\text { o nosso país. }\end{array}$ & $\begin{array}{l}\text { Sim. Por que podemos saber o } \\
\text { que houve a muito tempo atrás } \\
\text { e comparar com o presente. }\end{array}$ \\
\hline Aluno $\mathrm{G}$ & Aluno $\mathrm{H}$ & Aluno I \\
\hline $\begin{array}{l}\text { Não. Por que são coisas do } \\
\text { passado e apesar de serem } \\
\text { interessante não ajudam em } \\
\text { nada no nosso futuro apesar de } \\
\text { cair prova na faculdade não } \\
\text { serve pra nada. }\end{array}$ & $\begin{array}{l}\text { Sim. Por que ficamos sabendo } \\
\text { como nossos ancestrais se } \\
\text { comportavam nos séculos } \\
\text { antigos. }\end{array}$ & $\begin{array}{l}\text { Sim. Para sabermos mais sobre } \\
\text { nossos antigos moradores e } \\
\text { sobre a cultura que trouxeram } \\
\text { para nós. }\end{array}$ \\
\hline Aluno J & Aluno K & Aluno L \\
\hline $\begin{array}{l}\text { Sim. Para conhecer a história } \\
\text { do nosso passado, as coisas } \\
\text { mais importantes, que } \\
\text { ajudaram a construir o mundo } \\
\text { atual. }\end{array}$ & $\begin{array}{l}\text { Sim. Pois, descobri muito sobre } \\
\text { cada período, dos principais } \\
\text { momentos da revolução das } \\
\text { guerras até os dias atuais. }\end{array}$ & $\begin{array}{l}\text { Sim. Pois conhecimento é } \\
\text { poder, na história o poder se } \\
\text { reflete nos eventos históricos } \\
\text { importantes, } \\
\text { importantes do ocorrido na } \\
\text { sociedade. }\end{array}$ \\
\hline Aluno M & Aluno N & Aluno $\mathrm{O}$ \\
\hline $\begin{array}{l}\text { Sim. Porque além de tudo o } \\
\text { que já falei, também ficamos } \\
\text { sabendo de reinos, religiões, } \\
\text { linguagens que hoje foram } \\
\text { extintas, sabendo dos amores e } \\
\text { paixões etc. }\end{array}$ & $\begin{array}{l}\text { Sim. A história contribui em } \\
\text { nosso presente cotidiano para } \\
\text { desencadear o porque das } \\
\text { mudanças políticas e sociais. }\end{array}$ & $\begin{array}{l}\text { Sim. Para aprender sobre os } \\
\text { antepassados, mais muitos } \\
\text { coisas são desnecessárias para } \\
\text { algumas pessoas. }\end{array}$ \\
\hline
\end{tabular}

Fonte: pesquisa de campo realizada pelo autor - 2013

De acordo com o Quadro 01, podemos perceber que existe uma maioria de sujeitos que pensa a História de determinada forma, relacionando-a ao estudo exclusivo do passado, aos tempos remotos, e aos fenômenos que já não estão mais presentes em nossas vidas. Se atentarmos às respostas, apenas os Alunos $\mathrm{F}, \mathrm{I}, \mathrm{J}, \mathrm{K}$ e $\mathrm{N}$ fizeram alguma associação entre História e tempo presente, a partir das expressões: "dias atuais", "cultura que trouxeram pra 
nós", "ajudaram a construir o mundo atual", "até os dias atuais" e "contribui em nosso presente". Estes alunos, de alguma forma, têm a noção que atualmente buscamos para a História, que é de uma disciplina que esteja diretamente preocupada com as questões do presente, mesmo buscando, no passado, explicações para os fenômenos atuais.

É esse aspecto da relação, inclusive, que diferencia a História da Sociologia, pois se a primeira pretende estudar as transformações dos homens ao longo do tempo, ela não pode ficar retida apenas a um momento histórico. De acordo com Carretero (1997, p. 17):

[...] como visitar esse estranho país chamado passado? E como entender se foi bonito (feio ou trivial) enquanto durou? Coloquemos a questão em termos educacionais. Se um professor explica um aspecto do Império Romano está explicando História? Consideramos que a resposta não é necessariamente afirmativa. Se ele estiver somente descrevendo as características sociais e políticas desse período, talvez pudéssemos dizer que está ensinando sociologia do Império Romano, mas não História. Isto é, para que fosse considerado História deveriam incluir não somente os conhecimentos sobre o tempo passado mas também o estabelecimento de relações entre o passado e o presente ou, pelo menos, entre dois momentos no tempo.

Talvez, essa relação seja um dos momentos didáticos mais difíceis e complexos para os professores de História, visto que as diferenças tecnológicas, culturais, sociais, políticas e econômicas terminam, por influenciar, tanto os educadores quanto os alunos, que são filhos do seu tempo e tendem a compreender o passado com um olhar dos dias atuais. Nesse contexto, o passado se torna um tempo distante, sem relações com o presente, como podemos perceber nas respostas dos alunos A, B, C, D, E, H, L, M e O. Ou ainda de forma mais enfática, quando o aluno $\mathrm{G}$ coloca que não acha importante estudar História, pois "são coisas do passado e apesar de serem interessante não ajudam em nada no nosso futuro apesar de cair prova na faculdade não serve pra nada".

Nesse sentido, cabe-nos, enquanto professores de História, refletirmos acerca da nossa prática pedagógica e perguntarmo-nos: que relação estamos fazendo dos fatos passados com o presente? Que aproximação estamos fazendo dos conteúdos com a realidade dos sujeitos? Para que está servindo nossa disciplina? Questionamentos que devem fazer parte do cotidiano dos professores de História e que podem ser amenizados a partir da perspectiva da História local. 
Em relação às memórias discentes, buscamos investigar suas lembranças em relação aos sujeitos históricos e quando perguntamos quais as personagens que os alunos mais lembravam, obtivemos as respostas estruturadas nos quadros que se seguem:

Quadro 02: Personagens históricos mais lembrados pelos alunos - importância internacional

\begin{tabular}{|c|c|c|c|c|}
\hline Personagem & $\begin{array}{r}\mathrm{N}^{\mathrm{o}} \text { de } \\
\text { vezes que foi } \\
\text { citada }-1^{\circ} \text { ANO }\end{array}$ & $\begin{array}{c}\mathrm{N}^{\mathbf{o}} \text { de } \\
\text { vezes que foi } \\
\text { citada }-2^{\circ} \text { ANO }\end{array}$ & $\begin{array}{r}\mathrm{N}^{\mathrm{o}} \text { de } \\
\text { vezes que foi } \\
\text { citada }-3^{\circ} \text { ANO }\end{array}$ & Totais \\
\hline Adolf Hitler & 7 & 4 & 13 & 24 \\
\hline Napoleão Bonaparte & 1 & 7 & 1 & 9 \\
\hline Cristóvão Colombo & 0 & 7 & 2 & 9 \\
\hline Júlio César & 2 & 6 & 0 & 8 \\
\hline Vasco da Gama & 3 & 0 & 2 & 5 \\
\hline Alexandre & 2 & 1 & 0 & 3 \\
\hline Aristóteles & 2 & 1 & 0 & 3 \\
\hline Atenas & 2 & 0 & 0 & 2 \\
\hline Zeus & 2 & 0 & 0 & 2 \\
\hline Platão & 2 & 0 & 0 & 2 \\
\hline Rainha Elizabeth & 0 & 2 & 0 & 2 \\
\hline Maria Antonieta & 0 & 1 & 1 & 2 \\
\hline Faraós & 1 & 0 & 0 & 1 \\
\hline Sócrates & 1 & 0 & 0 & 1 \\
\hline Hamurabi & 1 & 0 & 0 & 1 \\
\hline Leonardo da Vinci & 1 & 0 & 0 & 1 \\
\hline Tristão e Isolda & 1 & 0 & 0 & 1 \\
\hline Rômulo e Remo & 0 & 1 & 0 & 1 \\
\hline Homo sapiens & 1 & 0 & 0 & 1 \\
\hline
\end{tabular}

Fonte: pesquisa de campo realizada pelo autor -2013 .

Quadro 03: Personagens históricos mais lembrados pelos alunos - importância nacional

\begin{tabular}{|c|c|c|c|c|}
\hline Personagem & $\begin{array}{c}\mathrm{N}^{\mathrm{o}} \mathrm{de} \\
\text { vezes que foi } \\
\text { citada }-1^{\circ} \text { ANO }\end{array}$ & $\begin{array}{c}\mathrm{N}^{\mathrm{o}} \text { de } \\
\text { vezes que foi } \\
\text { citada }-2^{\circ} \text { ANO }\end{array}$ & $\begin{array}{c}\mathrm{N}^{\mathrm{o}} \text { de } \\
\text { vezes que foi } \\
\text { citada }-3^{\circ} \text { ANO }\end{array}$ & Totais \\
\hline Pedro Álvares Cabral & 16 & 36 & 5 & 57 \\
\hline D. Pedro I & 14 & 22 & 6 & 42 \\
\hline D. Pedro II & 7 & 22 & 3 & 32 \\
\hline Getúlio Vargas & 19 & 9 & 3 & 31 \\
\hline Princesa Isabel & 3 & 11 & 3 & 17 \\
\hline Tiradentes & 1 & 9 & 2 & 12 \\
\hline Pero Vaz de Caminha & 0 & 5 & 0 & 5 \\
\hline Índios & 0 & 4 & 0 & 4 \\
\hline Lula & 3 & 0 & 0 & 3 \\
\hline D. João VI & 1 & 1 & 1 & 3 \\
\hline Juscelino Kubistchek & 0 & 3 & 0 & 3 \\
\hline Olga Benário & 0 & 3 & 0 & 3 \\
\hline Epitácio Pessoa & 2 & 0 & 0 & 2 \\
\hline Luiz Gonzaga & 2 & 0 & 0 & 2 \\
\hline Portugueses & 0 & 2 & 0 & 2 \\
\hline Aleijadinho & 1 & 0 & 0 & 1 \\
\hline
\end{tabular}

Revista de Pesquisa Interdisciplinar, Cajazeiras, n. 2, suplementar, p. 504-519, set. de 2017. 


\section{PROPEX}

\begin{tabular}{|l|l|l|l|l|}
\hline Luís Carlos Prestes & 0 & 1 & 0 & 1 \\
\hline Maurício de Nassau & 0 & 1 & 0 & 0 \\
\hline Escravos & 0 & 1 & 1 & 1 \\
\hline Santos Dumont & 0 & 0 & 1 & 1 \\
\hline Jango & 0 & 0 & 0 & 1 \\
\hline Mal Deodoro Fonseca & 1 & 0 & 1 \\
\hline
\end{tabular}

Fonte: pesquisa de campo realizada pelo autor - 2013

Quadro 04: Personagens históricos mais lembrados pelos alunos - importância local

\begin{tabular}{|l|c|c|c|c|}
\hline \multicolumn{1}{|c|}{ Personagem } & $\begin{array}{r}\mathrm{N}^{\mathbf{0}} \text { de } \\
\text { vezes que foi } \\
\text { citada }-1^{\circ} \text { ANO }\end{array}$ & $\begin{array}{c}\mathrm{N}^{\circ} \text { de } \\
\text { vezes que foi } \\
\text { citada }-2^{\circ} \text { ANO }\end{array}$ & $\begin{array}{c}\mathrm{N}^{\mathbf{o}} \text { de } \\
\text { vezes que foi } \\
\text { citada }-3^{\circ} \text { ANO }\end{array}$ & Totais \\
\hline João Pessoa & 1 & 5 & 0 & 6 \\
\hline Chica da Silva & 5 & 0 & 0 & 5 \\
\hline Zumbi dos Palmares & 0 & 3 & 0 & 2 \\
\hline Lampião & 0 & 2 & 0 & 1 \\
\hline Escrava Isaura & 1 & 0 & 0 & 3 \\
\hline
\end{tabular}

Fonte: pesquisa de campo realizada pelo autor -2013 .

Quadro 05: Alunos que não lembraram nenhum personagem ou não responderam

\begin{tabular}{|l|c|c|c|c|}
\hline \multicolumn{1}{|c|}{ Personagem } & $\begin{array}{r}\mathrm{N}^{\circ} \mathrm{de} \\
\text { vezes que foi } \\
\text { citada }-1^{\circ} \text { ANO }\end{array}$ & $\begin{array}{r}\mathrm{N}^{\mathbf{o}} \text { de } \\
\text { vezes que foi } \\
\text { citada }-2^{\circ} \text { ANO }\end{array}$ & $\begin{array}{r}\mathrm{N}^{\circ} \text { de } \\
\text { vezes que foi } \\
\text { citada }-3^{\circ} \text { ANO }\end{array}$ & Totais \\
\hline Não lembra & 12 & 11 & 6 & 29 \\
\hline Não respondeu & 5 & 2 & 0 & 7 \\
\hline
\end{tabular}

Fonte: pesquisa de campo realizada pelo autor - 2013

A história, enquanto campo de saber político e não neutro pode organizar o passado de acordo como o projeto político hegemônico deseja. Nos dizeres de Montenegro (1994, p. 15), “[...] essa forma de relacionar a história e a atividade política remete, irremediavelmente, à questão da memória”. Ele conclui que “[...] todo programa político, por sua vez, está associado à reconstrução do passado" (p. 15) e os programas escolares, por muito tempo, têm buscado a manutenção da lembrança de sujeitos que, transformados em heróis, acabam por respaldar a ideologia dominante.

Nesse sentido, se atentarmos aos dados dos quadros anteriores, podemos perceber que há uma divergência entre os principais personagens históricos lembrados pelos alunos, de acordo com o ano que estudam. Enquanto no primeiro ano o personagem mais lembrado foi Getúlio Vargas, no segundo ano, Pedro Álvares Cabral foi o mais lembrado com 36 citações. Já no terceiro ano, o personagem mais lembrado foi Adolf Hitler, com 13 menções por parte dos alunos. 
Esses resultados podem, à primeira vista, parecer coincidência, mas se pensarmos que a figura de Getúlio Vargas é estudada pelos alunos no nono ano do Ensino Fundamental, é provável que sua lembrança ainda esteja recente na memória dos mesmos durante o primeiro ano. O mesmo acontece com o segundo ano, que tem Pedro Álvares Cabral como o sujeito histórico mais citado, personagem de conteúdo do segundo ano; no terceiro ano, Adolf Hitler encabeça a lista dos mais lembrados, pois é sujeito importante na Segunda Guerra Mundial, conteúdo do terceiro ano.

Outro elemento importante de se discutir é que os personagens locais quase não são citados pelos alunos, pois, conforme podemos perceber, os quadros 02 e 03 - de lembranças de personagens de importância internacional e nacional - apresentam um número de citações muito superior ao quadro 04, que expressa as lembranças dos personagens locais pelos alunos. Nesse quadro, só aparecem cinco personagens que definimos como locais por centrarem suas lutas em um espaço territorial específico, mas que, mesmo assim, são reconhecidos nacionalmente. Dessa forma, temos indícios de que o Ensino de História não tem valorizado a contextualização de escalas menores da história, nem a luta dos sujeitos locais, centrando sua ação pedagógica, ainda, na perspectiva da valorização dos grandes sujeitos.

Como a história trabalha com fatos, atua na manutenção daquilo e daqueles que ela pretende que sejam lembrados, do que ou de quem se pretende que seja esquecido. Em outras palavras, a História se utiliza ativamente da memória individual e da coletiva. Lembrar os heróis nacionais, esquecer os movimentos populares organizados, durante muito tempo, tem sido a lógica da história a serviço do Estado.

No campo individual, conforme nos coloca Le Goff (1996), a memória pode ser estudada pela psicologia, psicofisiologia, neurofiosiologia, biologia, ou, ainda, pela psiquiatria. Nesse sentido, o autor caracteriza a memória no âmbito individual, afirmando que

A memória, como propriedade de conservar certas informações, remete-nos em primeiro lugar a um conjunto de funções psíquicas, graças às quais o homem pode atualizar impressões ou informações passadas, ou que ele representa como passadas. (LE GOFF, 1996, p. 423).

Reservadas as devidas proporções, as comparações, quer sejam elas metafóricas ou concretas, entre a memória individual e a memória coletiva são concebíveis, e suas utilizações podem, muitas vezes, segundo Le Goff, evocar "traços e problemas da memória histórica e da 
memória social” (p. 423). Dessa forma, o esquecimento ou amnésia individual também se manifesta no nível da memória coletiva, que termina por afetar a identidade de determinados grupos sociais. Le Goff (1996, p. 425) nos esclarece, ainda, que,

Por outro lado, num nível metafórico, mas significativo, a amnésia não é só uma perturbação no indivíduo, que envolve perturbações mais ou menos graves da presença da personalidade, mas também a falta ou a perda, voluntária ou involuntária, da memória coletiva nos povos e nas nações que pode determinar perturbações graves de identidade coletiva.

O historiador, como um profissional que trabalha com a construção das experiências vividas pela sociedade, e que, muitas vezes, esteve à disposição das camadas dominantes, seleciona os acontecimentos, não de forma ingênua e neutra, mas de acordo com as necessidades de manutenção da permanência dessas camadas dominantes, como suporte ideológico e político do poder.

Dessa forma, mesmo com mudanças recentes e uma legislação que buscam considerar os sujeitos comuns como importantes para a História, sua prática pedagógica ainda encontrase muito centrada na valorização de heróis, como podemos perceber a partir dos quatro personagens mais citados pelos alunos (Pedro Álvares Cabral, D. Pedro I, D. Pedro II e Getúlio Vargas). Podemos afirmar que essa situação ainda é um ranço da ideia de que a história, enquanto processo vivido, é conduzida pela ação de indivíduos iluminados, o que é enfatizado pelo Estado, que alimenta e incentiva o culto aos heróis nacionais. Lopes e Galvão (2001, p. 34) nos esclarecem sobre essa questão, quando afirmam:

Sabemos que, principalmente no século XIX, no afã de tornar-se ciência, a História priorizou a história política, a ação dos indivíduos na condução e transformação dos fatos históricos (gerando aquilo que hoje chamamos de culto aos heróis e às datas) e o documento oficial como a fonte mais legítima para a pesquisa (causando o que atualmente podemos identificar como o deslumbramento e o fetiche diante do documento).

Ou ainda Abud (1998), quando trata das narrativas históricas escolares, como momentos guiados pelos manuais impostos pelo Estado, recorrendo a mitos de fundação, à evocação de heróis nacionais e episódios épicos costurados de forma epopeica. Essa prática coloca a nação como um organismo vivo, a partir de uma metáfora biológica: que nasce, 
cresce e se torna madura de forma evolutiva. Para isso, se faz necessário a criação de uma identidade homogênea, capaz de não deixar as diferenças aflorarem. A educação histórica passa então a ser um caminho para constituição dos súditos no processo de coesão da nação.

Percebemos, assim, que a história foi-nos imposta de forma positivista, com uma visão europeizada, preocupada, principalmente, com aspectos políticos e a ação dos homens considerados heróis. Porém, outro aspecto que é importante refletir parte da seguinte questão: atualmente, até que ponto o ensino de História ainda consegue formar a ideia de um herói nacional como condutor dos processos históricos? Pois, se atentarmos o Quadro 05, há vinte e nove indicações de alunos que não lembram de nenhum personagem histórico estudado, situação que nos leva a refletir sobre quais as práticas de ensino de História têm sido desenvolvidas nas escolas. Estamos substituindo um ensino pautado na memorização e na apreensão de conteúdos por qual prática pedagógica?

Outro aspecto que consideramos importante é que nas últimas décadas a abertura da negociação entre esferas do governo e os movimentos sociais vem gerando um diálogo que tem proporcionado a abertura e a flexibilização dos programas escolares em relação também aos conteúdos. Nesse contexto, sujeitos, outrora deixados de lado, têm conquistado seus espaços no currículo escolar, como é o caso dos negros e índios, que através da Lei 10.639/2003 e da Lei 11.645/2008 vislumbram a possibilidade de terem suas histórias e culturas consideradas e visibilizadas nas escolas. Porém, sua real efetivação é um desafio complexo e vem sendo enfrentado por muitos professores e pelos próprios sujeitos que demandam essa nova realidade educacional.

Por fim, e não menos importante, questionamos aos alunos quais os conteúdos que eles estudaram em História e que tem maior relação com as suas vidas, o que nos levou a estruturar o quadro que se segue:

Quadro 06: Conteúdos de História mais significativos para os alunos

\begin{tabular}{|c|c|c|}
\hline Aluno A & Aluno B & Aluno C \\
\hline $\begin{array}{l}\text { As inovações tecnológicas que } \\
\text { acontece na } 2^{\circ} \text { Revolução Industrial. }\end{array}$ & Sobre os índios. & Nenhum. \\
\hline Aluno D & Aluno E & Aluno F \\
\hline Nenhum. & Nenhum. & $\begin{array}{l}\text { Libertação dos escravos, } \\
\text { os índios e o cangaço. }\end{array}$ \\
\hline Aluno $\mathrm{G}$ & Aluno $\mathrm{H}$ & Aluno I \\
\hline Nenhum & Não sei. & Nada. \\
\hline Aluno J & Aluno K & Aluno L \\
\hline
\end{tabular}




\begin{tabular}{|l|l|l|}
\hline A colonização Portuguesa. & $\begin{array}{l}2^{\circ} \text { Revolução Industrial, pois } \\
\text { com o surgimento do telefone e } \\
\text { radio facilitou a vida de todos e } \\
\text { são usados até hoje. }\end{array}$ & \\
\hline Aluno M & \multicolumn{1}{|c|}{ Aluno N } & Aluno O \\
\hline $\begin{array}{l}\text { Iluminismo, Nazismo, Fascismo, } \\
\text { escravidão dos negros "para entender } \\
\text { e respeita ainda mais as diferenças } \\
\text { para não ter preconceitos", os }\end{array}$ & $\begin{array}{l}\text { As posições de alguns nomes } \\
\text { históricos e revolucionários } \\
\text { passaram para mim a coragem, e } \\
\text { a importância da minha voz na } \\
\text { Espartanos que mataram os } \\
\text { siferentes assim que nasciam, pois } \\
\text { eles não seriam fortes o suficiente (e } \\
\text { eu como deficiente física discordo } \\
\text { plenamente). }\end{array}$ & \\
\hline
\end{tabular}

Fonte: pesquisa de campo realizada pelo autor- 2013 .

Percebemos no quadro que a maioria dos alunos (C, D, E, G, H, I, L e O) não percebem relação alguma dos conteúdos e ensino de História com suas vidas, o que se dê, talvez, por compreenderem a educação em aspectos utilitários, pois eles não conseguem aplicar os conteúdos de História em elementos práticos dos seus cotidianos, o que lhes é muito cobrado, principalmente quando se inserem no mundo do trabalho. Nesse sentido, perguntamo-nos: para que serve estudar História? Em se tratando dos alunos, existe uma função prática para esta disciplina? Se pensarmos a educação meramente como uma prática de formação para o mercado de trabalho, não iremos encontrar respaldo para o Ensino de História nas escolas.

Por outro lado, a educação escolar tem se constituído como um serviço social para formação dos sujeitos de maneira integral, ultrapassando as barreiras de um ensino para profissionalização. Assim, a História se apresenta como um campo de saber importantíssimo, pois relaciona o tempo atual aos tempos passados, investigando as mudanças e permanências humanas ao longo dos tempos, atuando, diretamente, na construção das identidades dos sujeitos, que quanto mais compreensão histórica tiverem, mais censo de cidadania lhes será proporcionada; mesmo porque eles poderão perceber que muitas conquistas, de hoje, são frutos de um processo histórico de luta, conforme nos esclarece Bittencourt (2001, p. 20)

O ensino de História deve contribuir para libertar os indivíduos do tempo presente e da imobilidade diante dos acontecimentos, para que possa entender que a cidadania não se constitui em direitos concedidos pelo poder instituído, mas tem sido obtida em lutas constantes e em suas diversas dimensões. 
Nesse sentido, podemos perceber o entendimento desta relação proposta pela História nas respostas dos alunos A, B, F, J, K, M e N, pois os mesmos conseguem associar os conteúdos às suas vivências. Nesse caso, quando o Aluno 1 afirma que "[...] as inovações tecnológicas que acontece na $2^{\circ}$ Revolução Industrial" tem relação com sua vida; ou ainda, quando o Aluno $\mathrm{K}$ responde que a " $2^{\circ}$ Revolução Industrial, pois com o surgimento do telefone e rádio facilitou a vida de todos e são usados até hoje", fica claro que a leitura e o uso que eles fizeram do conteúdo ensinado na disciplina de História teve um sentido e lugar na sua possível formação de cidadãos, pois compreenderam que as tecnologias da informação e comunicação, presentes no mundo de hoje, são resultados de um longo processo histórico. Mesmo que isso não signifique uma formação cidadã, temos a construção de competências e habilidades do conhecimento histórico por parte desses alunos.

O caso do Aluno B é bastante especifico, pois o mesmo percebe que os conteúdos de História têm mais relação com sua vida quando tratam das questões indígenas; isso se dá porque o mesmo é descendente de índios e sua avó faz parte de uma tribo de Potiguaras, localizada na cidade de Baía da Traição, no Estado da Paraíba. Mesmo assim, de alguma forma, ele não deixa de associar o conteúdo/ensino de História com algum aspecto da sua realidade, o que contribui para o fortalecimento de sua identidade, individual ou coletiva, dentro da sociedade.

Específico também é o caso do Aluno M, que tem deficiência física, e que, diante das dificuldades impostas por tal situação, associa os conteúdos de História à sua realidade. Quando relacionou o conteúdo da Grécia com os dias atuais, ao afirmar que: "Os Espartanos que mataram os diferentes assim que nasciam, pois eles não seriam fortes o suficiente (e eu como deficiente física discordo plenamente)", ela comparou dois momentos e duas formas distintas de se enfrentar um mesmo problema - a deficiência física - e pode chegar às suas conclusões, mesmo refletindo a partir de valores culturais da modernidade. Ela se colocou como sujeito que pensa a história de forma crítica. $O$ que converge para o que afirma Bittencourt (2001, p. 19), quando trata do Ensino de História como prática pedagógica problematizante: "A inovação que ocorre é a ênfase atual ao papel do ensino de História para a compreensão do 'sentir-se sujeito histórico' e em sua contribuição para a 'formação de um cidadão crítico"”. 
$\mathrm{Na}$ escola, o Ensino de História pode contribuir na formação de alunos críticos, que possam entender e relacionar diversas realidades, tanto do tempo presente, quanto dos tempos passados; condição essencial para formação da cidadania. Ainda de acordo com Bittencourt (2001, p.20):

\begin{abstract}
A História deve contribuir para a formação do indivíduo comum, que enfrenta um cotidiano contraditório, de violência, desemprego, greves, congestionamentos, que recebe informações simultâneas de acontecimentos internacionais, que deve escolher seus representantes para ocupar os vários cargos da política institucionalizada. Este indivíduo que vive o presente deve, pelo ensino da História, ter condições de refletir sobre tais acontecimentos, localizá-los em um tempo conjuntural e estrutural, estabelecer relações entre os diversos fatos de ordem política, econômica e cultural, de maneira que fique preservado das reações primárias: a cólera impotente e confusa contra os patrões, estrangeiros, sindicatos ou o abandono fatalista da força do destino.
\end{abstract}

Compreendemos, então, que uma das formas de aproximar a História da realidade dos alunos é fazê-lo pelo viés da História Local, de forma que os mesmos possam compreender-se sujeitos históricos. Assim, muitos professores de História têm se utilizado dessa prática, com o intuito de perceber acontecimentos micros, buscando a minúcia dos dados, com a finalidade de acrescentar novos elementos à construção histórica. Como nos coloca Barbosa (2005), essa prática é uma "[...] relação entre a utilização da abordagem em escala como possibilidade de um movimento relacional entre o pormenor e o todo" (p. 46). Por isso, essas escalas de análise histórica da realidade micro ou da macro não podem ser analisadas como opositoras, mas como complementares, uma vez que a perspectiva do local se apresenta como um recurso teórico-metodológico diversificado para a construção da história. Pois, é necessário estudar a localidade, sem perder de vista sua relação com um processo maior. Podemos nos aproximar de determinada época, podemos descobrir como as pessoas se relacionavam, como viviam em grupo.

É preciso perceber, também, que a realidade local faz parte de um contexto mais amplo e não pode ser dissociada do mesmo, o que provocaria fragmentação e reducionismo histórico. Nos dizeres de Barbosa (2005, p. 27),

É importante estar atento para o fato de que a abordagem local, metodologicamente falando, tem o seu sentido garantido, 
principalmente se tomada como parte do sistema maior que a integra: a região, o estado nacional, o contexto internacional.

A partir do uso da História Local, o professor de História pode garantir aos educandos competências e habilidades que lhes garantam compreender melhor o conhecimento histórico "[...] a partir de recortes selecionados, pero integrados y conectados con el conjunto del conocimiento. Es la conjunción de la garantia del conocimiento científico con los objetivos educativos" (OSSANNA, 1994, p. 63). Reforçando essa ideia, na esfera educacional, através da História Local, os alunos podem ter resgatada sua memória coletiva, percebendo-se como agentes históricos. Dessa forma, esses sujeitos têm consciência de si mesmos dentro do coletivo e se envolvem com sua identidade social.

\section{CONSIDERAÇÕES FINAIS}

Cientes das limitações presente no referido artigo, buscamos compreender um elemento problema no Ensino de História. Por outro lado, compreendemos suas potencialidades e possibilidades para o (re) pensar práticas pedagógicas dos professores de História. Compreendemos e verificamos que o Ensino de História se transformou ao longo dos últimos anos, o que abriu possibilidades de se pensar sujeitos outrora "esquecidos" nos manuais escolares. Porém, ainda experimentamos resquícios de um fazer pedagógico bancário, a partir da verbalização exclusiva dos conteúdos e do entendimento dos alunos como vazios de conhecimentos.

A partir da presente pesquisa, percebemos que o Ensino de História tem se caracterizado como uma prática de viés elitista e que tem defendido as ideias dos vencedores. Dessa forma, sua organização tem se perpetuado como de reverenciamento às elites políticas, econômicas e sociais, confirmando seu status de superioridade cultural em relação às massas populares, entendidas como ignorantes, conduzidas historicamente pelos grandes homens.

Vivenciamos, porém, uma lenta abertura do currículo escolar para a consideração de sujeitos que foram antes silenciados na história. Bem recentemente, a História ensinada na escola vem incorporando os sujeitos populares e suas lutas, não mais como revoltosos incidentes históricos, mas como grupos que defendem seus ideais de justiça e melhorias de 
vida. Mesmo assim, a prática de Ensino de História ainda sofre com o ranço da memorização, com a perspectiva da elevação dos heróis em detrimento do povo.

As nossas constatações em relação ao que os alunos pensam sobre o Ensino de História giram em torno das suas indiferenças em relação à disciplina. A maioria não percebe relações entre os conteúdos trabalhados e suas realidades, ou com suas expectativas de vida. Muitos acham que a História deveria ser trabalhada de maneira mais dinâmica, a partir da pesquisa e da investigação em seus espaços sociais.

Recentemente, precisamos pesquisar e discutir acerca das propostas que vêm sendo empreendidas pelo Estado em relação à Educação e ao Ensino de História. Propostas como o fenômeno da Escola sem Partido e da Base Nacional Comum Curricular desafiam à sociedade a pensar e agir em relação ao modelo de educação que se deseja para os jovens do país. Assim, encerramos com questões que não se respondem aqui, mas que se colocam como desafios para professores, alunos, famílias, comunidade escolar, futuros profissionais: que modelo de educação queremos? O Ensino de História precisa se reestruturar? De que maneira? Que memória estão em manutenção? Há lugar para os movimentos de baixo no novo currículo de História que se apresenta?

\section{REFERÊNCIAS BIBLIOGRÁFICAS}

ABUD, Kátia. Currículos de História e políticas públicas: os programas de História do Brasil na escola secundária. In: BITTENCOURT, Circe Maria F. (Org.). O saber histórico na sala de aula. 2. ed. São Paulo: Contexto, 1998, p. 28-41.

BARBOSA, Vilma de Lurdes. Contribuições para pensar, fazer e ensinar história local. Tese de doutorado em Educação. Programa de Pós-Graduação em Educação. Natal: UFRN, 2005.

BITTENCOURT, Circe Maria Fernandes (Org.). Capitalismo e cidadania nas atuais propostas curriculares de História. In: O saber histórico na sala de aula. 5 ed. São Paulo: Contexto, 2001, p. 11-27.

BRASIL. Lei $\mathbf{n}^{\mathbf{0}}$ 11.645, de 10 de março de 2008. Altera a Lei $\mathrm{n}^{\circ}$ 9.394, de 20 de dezembro de 1996, para incluir no currículo oficial da rede de ensino a obrigatoriedade da temática: História e Cultura Afro-Brasileira e Indígena. Diário Oficial da União [da República Federativa do Brasil], Brasília, DF, seção 1, p.1, 10 mar. 2008. Disponível em: <http://www.planalto.gov.br/ccivil_03/_ato2007-2010/2008/lei/111645.htm> Acesso em: 02 ago. 2017. 
CARRETERO, Mario; trad. Beatriz Affonso Neves. Construir e ensinar: as Ciências Sociais e a História. Porto Alegre: Artes Médicas, 1997.

LE GOFF, Jacques. História e memória. Campinas, SP: Editora da Unicamp, 4 ed., 1996.

LOPES, Eliane Marta Teixeira e GALVÃO, Ana Maria de Oliveira. História da educação. Rio de Janeiro: DP\&A, 2001.

MONTENEGRO, Antonio Torres. História oral e memória: a cultura popular revisitada. São Paulo: Contexto, 3 ed., 1994.

OSSANA, Edgardo O. Una alternativa em la enseñanza de la História: el enfoque desde lo local, lo regional. In: VÁZQUEZ, Josefina Z. Enseñanza de la História. Buenos Aires, 1994 [Colección Interamer, 29]. 